\title{
Analysis and Suggestions for Foreign Students' Education Management System Improvement in China: Based on a Case Study of Shanghai
}

\author{
Canjing $\mathrm{Ma}^{1}$, Yinqiu $\mathrm{Ma}^{2 *}$ \\ ${ }^{1}$ School of Teacher Education, Jiangsu University, Zhenjiang, China \\ ${ }^{2}$ Business School, Nanjing Normal University, Nanjing, China \\ Email: *annitama@126.com
}

How to cite this paper: Ma, C.J. and Ma, Y.Q. (2019) Analysis and Suggestions for Foreign Students' Education Management System Improvement in China: Based on a Case Study of Shanghai. Open Journal of Social Sciences, 7, 116-127.

https://doi.org/10.4236/jss.2019.76009

Received: May 11, 2019

Accepted: June 16, 2019

Published: June 19, 2019

Copyright $\odot 2019$ by author(s) and Scientific Research Publishing Inc. This work is licensed under the Creative Commons Attribution International License (CC BY 4.0).

http://creativecommons.org/licenses/by/4.0/

\begin{abstract}
Education management for foreign children in primary and secondary schools has become an issue unignorably in promoting the internationalization of education in China. This paper clarifies the characteristics of the formalization of "learning in regular class" and the classification of foreign students' education management through analyzing the foreign students' admission policies formulated and promulgated by Shanghai Municipal Education Commission. Combined with analyses on the characteristics of the foreign students' education management system in Japan's primary and secondary schools, this paper proposed some improvement suggestions. For example, Shanghai should strengthen the construction of the Chinese language teaching system, actively promote the close cooperation between the education administrative departments at all levels and the schools while fully considering the diversity of foreign students to maintain their cultural characteristics.
\end{abstract}

\section{Keywords}

Primary and Secondary Schools in Shanghai, Policies, Foreign Students, Education Management System

\section{Introduction}

According to the statistics of the Shanghai Municipal Education Commission, in 2004, there were 2 thousand foreign students studying in 150 primary and secondary schools that have been approved by the Municipal Education Commission with the qualification to admit foreign students. By 2020, the number of foreign students in Shanghai at school age will reach 100,000 [1]. With the con- 
tinuous improvement of Shanghai's living, educational, medical facilities and other hardware facilities, more and more children with foreign nationalities choose to attend local primary and secondary schools in Shanghai.

Actually, Chinese Ministry of Education officially adopted and issued the "Interim Measures for the Management of Primary and Secondary Schools for Foreign Students' admission" in July 1999 (hereinafter referred to as the "Interim Measures") to standardize the admission procedure and teaching management system of primary and secondary schools in order to facilitate foreign students to receive education in China. In January 2000, the Shanghai Municipal Education Commission promulgated the specific implementation regulations "Implementation Rules for the Administration of Foreign Students in Primary and Secondary Schools for Foreign Students' Admission" (hereinafter referred to as the "Implementation Regulations"). In order to further optimize the investment and talent introduction environment in Shanghai and standardize the admission of foreign students (children) by primary and secondary schools and kindergartens, the Shanghai Municipal Education Commission issued "Shanghai Municipal Educational Commission's Notice on Regulations on Foreign Students' (Children) Admission by Primary and Secondary Schools and Kindergartens in Shanghai" (hereinafter referred to as Notice I) and "Shanghai Municipal Educational Commission, Shanghai Municipal Price Bureau and Shanghai Municipal Finance Bureau's Notice on Standardization of Toll Management for Foreign Students' (Children) Admission by Public Primary and Secondary Schools and Kindergartens in Shanghai" (hereinafter referred to as Notice II) in November 2006 and March 2007 respectively.

At present, the foreign students mainly study in Shanghai in two forms: 1) they are fully learning in regular class without international department in the school; 2) there is an "international division" providing teaching activities for foreign students only and foreign students can apply for learning in regular class after they meet academic requirements [2] [3]. Taking the Japanese in Shanghai which represent the largest number of foreigners in Shanghai as an example, the proportion of foreign students who are newcomers in Shanghai being sent to local school's "international division" for foreign students only in Shanghai and the number of students who transfer from Japanese schools or naturally enter the "international division" are rising [4].

\section{Problems on Educational Management System for Foreign Students}

However, Shanghai's latest education management system for foreign students was made in 2007, nearly 12 years ago. At that time, the school training mechanism, resource security and others were far worse than the current goal of international talent education and training, which caused the divergencies between the foreign student education management system and their actual needs now. Since the local school's teaching systems, teaching methods and teaching resources have long been targeted only for Chinese students, there are many 
problems and bottlenecks in the education management of foreign students. For example, 1) the management system, curriculum, and teachers recruitment are carried out independently in the "international division", where is only limited to foreign students during daily learning life, lacking of interaction with Chinese students. In addition, the information exchange is not smooth, and there is a severe lack of cooperation and interaction among the "international division" of all schools because of no external support [5].2) Cultural differences such as the flag-raising ceremony, patriotic education and others cause that students' do not adapt to the school management system and teaching activities. 3) There are problems in Chinese language teaching for foreign students, such as Chinese teacher structure disorders, the shortage of teachers, and the low satisfaction of teaching materials [6].

In conclusion, an out-of-date education system and management model of public primary and secondary schools are unable to meet the needs of foreign students which leads to the inadequate guarantee of right to education for all children. There is an urgent need for Shanghai to improve a set of more scientific and detailed policies, laws and regulations on the educational management for foreign students and schools, enabling school administrators and government authorities to have laws and activities in their actions to solve realistic problems.

\section{Problems' Background}

\subsection{The Diversified Development of Foreign Students Requires Inclusive Management System}

The "2006 Bulletin on the Development of Labor and Undertaking of Social Security" issued by the Ministry of Labor and Social Security shows that by the end of 2006, the number of foreigners working in China with foreigner employment permit was 180,000 , nearly double the number at the end of 2003. Among them, more than half of foreigners have long-term residency in employment or business, and most of them take senior management positions and senior technical positions [7]. According to the statistics of the Exit-Entry Administration of the Ministry of Public Security in 2007, among the permanent foreign resident population, the proportion of foreign workers in foreign-funded enterprises is the highest, reaching $28.3 \%$. And family members take the second largest proportion, reaching $20.1 \%$. And the children with foreign nationalities in kindergartens, primary schools and secondary schools take the proportion of 3.3\%. It can be seen that the foreigners in Shanghai today are mainly "family migration". As for nationality, the top 10 are Japan, the United States, South Korea, Singapore, Germany, Malaysia, France, Canada, the United Kingdom and Australia. According to the statistics of the sixth national census in 2010, the number of foreigners living in China and receiving census registrations rose to 593,832. Shanghai ranks first in China with 143,200 foreigners, accounting for $24.1 \%$ of the total [8]. Compared with 2007, there are subtle changes in the composition of nationality. Except for traditional developed countries such as Japan, the 
United States and South Korea, foreigners come from developing countries such as India, Indonesia, Thailand and the Philippines also in an increasing trend. In addition, with the continuous return of overseas students and the traditional overseas Chinese, the increase in cross-border marriages, there are more and more foreign nationalities' children with different languages, cultural backgrounds and educational needs studying in Shanghai. They are constantly integrating into Shanghai's basic education system, which has brought great challenges to the construction of the school's education management system.

\subsection{Influences from the International Education Concept with Development of Globalization}

With the increasing of international status and improvement of international participation capabilities of China, there is an urgent need to unify the legal system applicable to norms and international treaties. So far, China has signed international agreements such as the "International Convention on Economic, Social and Cultural Rights" and the "International Convention on the Rights of the Child". Furthermore, the development of the international understanding of education and multicultural education requires the reform of the school education system to consider the needs of foreign students and their coexistence with local ones. The arrival of the era of internationalization demands all nations and countries to cultivate citizens not only with international sense of responsibility, international consciousness, international communication skills, but also with a profound understanding of multiculturalism and multiple system. Multicultural education strongly emphasizes and opposes racism and other forms of discrimination in schools and societies, recognizes and accepts the diversity of students (including nation, race, language, religion, economy and gender) and requires insurance of their experience on educational equity, educational success and social mobility during the teaching reform, and the design of education program should meet the needs of different groups, considering the differences in nation, race, language, religion, economy and gender. On the other hand, the core value of the education for international understanding emphasizes that it should be based on human symbiosis and coexistence, and regard heterogeneous culture as an inclusive object that can coexist.

However, the policies formulated at that time cannot meet the two requirements mentioned above. The construction of the foreign students' education management system began in 1999, and Shanghai in 2000 when China was about to join the WTO. According to the relevant provisions of the General Agreement on Trade in Services (GATS), education service is one of the basic services that member states must make market access commitments [9]. According to China's commitments to education service when joining in WTO, education and compulsory education in special fields such as military, police, politics and party school are not open to the outside world. However, China promises to allow foreign countries to provide education services in primary education, secondary 
education, high education, adult education and other education forms; in the provision of educational services, there is no commitment to cross-border delivery; there are no restrictions on overseas education consumption; foreign qualified individual education service providers with certain qualifications are allowed to provide education services to China after be hired or invited by Chinese schools and educational institutions. It can be seen that the impact of joining the WTO on Chinese education is comprehensive and multi-angled. With the opening of the education market, in order to protect the sovereignty of education and cultural security, strengthening the construction of foreign-related laws and regulations in primary and secondary schools has become one of the important corresponding means [10] [11]. On the other hand, according to the purpose mentioned in "Interim Measures" as "adapting to the needs of the development of China's reform and opening up, providing convenience to foreign students' attending China's primary and secondary schools and promoting international exchanges of China's primary and secondary schools" at the time, regulation was formulated mainly for solving the realistic problems of foreign students' study at primary and secondary schools but not promoting the concept of international understanding education.

\section{Characteristics of Education Management System for Foreign Students in Shanghai Primary and Secondary Schools}

\subsection{Transition of Related Policies}

\section{Regulation from the Ministry of Education of China}

A total of 12 terms are included in "Provisional Management Measures on Admission of Foreign Students by Primary and Secondary Schools" formulated by the Ministry of Education of China, which has been stipulated mainly aiming at foreign students' admission qualifications, the qualifications for foreign students' admission of primary and secondary schools, and the student status and study management for foreign students. Meanwhile, the authority and responsibility of the educational administrative departments at the provinces, autonomous regions and municipalities directly under the Central Government level have been deployed.

The "Implementation Regulations" and the two "Notices" formulated by the Shanghai Education Commission

For the purpose of "meet the needs of the reform and opening up and standardizing the foreign students' education management in China", Shanghai Education Commission formulated the "Implementation Regulations" what consists of 5 chapters and 18 articles, including the qualifications and necessary conditions (for foreign students and schools), the approval of school's admission qualifications, school management, and the management responsibilities and obligations of administrative departments and schools are stipulated detailed.

With respect to responsibilities and obligations of administrative depart- 
ments, first of all, in terms of qualification approval of school's admission qualifications, the specific steps are as followed. After passing the review by the District Education Bureau, school should have to accept on-site inspection by the Shanghai Municipal Education Commission and the Foreign Affairs Office of the Shanghai Municipal People's Government and the Shanghai Public Security Bureau. The school has to report to the Ministry of Education of the People's Republic of China to make a registration after being approved, which can enroll foreign students. Secondly, the responsibilities of the relevant administrative agencies at each level are regulated as follows. The district and county education bureaus are the competent departments for coordinating and handling the daily management and foreign affairs of foreign students, while the municipal education commission is the centralized management department for foreign students.

As for education management at school level, the regulation is mainly focused on teaching management, administrative affairs management, and student's status management. First of all, "schools should organize and implement educational management for foreign students on the basis of the current education program in China", "Except for necessary Chinese lessons arranged advanced, any separate classes for foreign students only is generally unavailable in the teaching process. Chinese is the basic instructional language", "Foreign students are exempted from ideological moral courses and ideological political courses. Schools can organize their participation in social practice activities such as public welfare labor according to the requirements of the curriculum", "In addition to equipped the corresponding teaching staff, the teachers engaged in teaching must occupy a certain proportion of middle and senior positions" etc are regulated as teaching management. Secondly, "There must be designated departments and managers to take responsibility for foreign students", "The schools have a living condition suitable for foreign students", "There must also be sound rules and regulations as well as high-quality services and security personnel" were stipulated concerning on administrative affairs management. Finally, student status management was regulated as "referring to the Measures for the Management of Primary and Secondary School Registration in Shanghai."

After that, Shanghai Education Commission issued "Notification 1" and "Notification 2" in 2006 and 2007 respectively. The "Notification 1" further distinguish the identity of foreign students, which divide them into children who come to Shanghai accompanying their parents as worker (accompanying children) and students who apply directly to Shanghai to attend primary and secondary schools from abroad (overseas students). Schools that can receive the latter are limited to "schools with permission to admit foreign students' directly from abroad". This kind of schools can accept foreign students who apply directly from overseas to attend primary and secondary schools under the premise of admission plan for city students after approved by the Shanghai Municipal Education Commission. And schools can independently develop educational programs based on the actual situation of foreign students. "Notification 2" drafts 
specific tuition standards for public primary and secondary schools. The detailed data is shown in Table 1.

According to two notifications, foreign students (accompanying children) whose parents live in Shanghai can be arranged by the education Bureau to attend public primary and secondary schools according to the principle of proximity so as to district school's admission. Accompanying children are further classified into three types according to their parent's identities such as "overseas Chinese children", "children of foreigners holding Shanghai residence permit B certificate" and "children of overseas students with Shanghai residence permit B certificate" while their tuition standards and admission systems are also different in the light of identities. If they receive compulsory education in Shanghai, the cost is the same as that of the city's registered students who are free from tuition and miscellaneous fees.

Based on relevant regulations promulgated by the Shanghai Municipal Education Commission, each administrative region (county) has also formulated specific policies and measures in accordance with their respective conditions. For example, Pudong formulated "Guidance on the admission of foreign students (infants) for primary and secondary schools and preschool kindergartens in $\mathrm{Pu}$ dong new area" in July 2007 and "Notice on management of foreign students' admission and status management" in August 2008. In addition, Minhang district promulgated "Management measures for foreign students' admission in primary and secondary schools in Minhang district" in August 2007, and Changning district formulated "Guidance notes for the admission of foreign students in primary and secondary schools". Putuo district also announced the transient measures for foreign students in primary and secondary schools through the Education Bureau's official website in 2010. Shanghai has basically formed a system for admitting foreign students at all levels of supervision by all levels of the administrative departments till now.

\subsection{System Characteristics}

Through analyses on the policies and measures mentioned above, the characteristics of educational management system for foreign students in primary and secondary schools in Shanghai should be concluded as follows:

Firstly, supervision of administrative authorities at all levels tends to be more rigorous and systematic, which mainly reflected in the strict examination system

Table 1. Tuition and other fees for school-aged children in Shanghai.

\begin{tabular}{|c|c|c|c|c|}
\hline \multirow{2}{*}{ Expenditure } & \multicolumn{2}{|c|}{$\begin{array}{l}\text { Public schools which are permitted to admit } \\
\text { "accompanying children" }\end{array}$} & \multicolumn{2}{|c|}{$\begin{array}{l}\text { Public schools which are permitted to admit "overseas students" } \\
\text { with qualification to develop educational programs independently }\end{array}$} \\
\hline & Primary schools & $\begin{array}{l}\text { Secondary schools (including } \\
\text { secondary vocational schools) }\end{array}$ & Primary schools & $\begin{array}{l}\text { Secondary schools (including } \\
\text { secondary vocational schools) }\end{array}$ \\
\hline Tuition & $3000 \mathrm{RMB}$ per semester & $6000 \mathrm{RMB}$ per semester & $\begin{array}{l}\text { 34,000 RMB per semester } \\
\text { (upper limit) }\end{array}$ & $\begin{array}{l}\text { 38,000 RMB per semester } \\
\text { (upper limit) }\end{array}$ \\
\hline Accommodation fee & & $9000 \mathrm{RMB}$ per semester & & $1300 \mathrm{RMB}$ per semester \\
\hline
\end{tabular}


for school's foreign students' admission qualifications and clarifying the management responsibility of administrative organs at all levels.

Secondly, at the school level, the teaching management system based on the admission procedure and students' status management of foreign students has been initially established. The current system advocates teaching activities for foreign students under the form of class attendance. "study in regular class" advocates that foreign students study together with Chinese students, promoting foreign students and Chinese students to Advocating foreign students and Chinese students to study in the same class, promoting foreign students and Chinese students to understand each other's different cultures and respect multiculturalism, which provides the possibilities for schools to promote international understanding education and to cultivate outstanding global citizens. However, the current system does not further stipulate implementation concretely.

Finally, the admission conditions and qualifications of foreign students are typified and differentiated. The classification of foreign students and the setting of different charging standards are draw on the experience of United States and other countries.

With the parents as the taxpayer as the standard, the children with foreign nationalities who contribute to the economic development only are arranged to attend school nearby and the children of the talents are relieved of tuition fees based on principle that "education as a reward", which allows some of the accompanying children to have the opportunity to treated as Chinese national students when they receive education at primary and secondary schools, and to a certain extent, the right to education for specific type of children is guaranteed. However, it also leads to the inequality of education opportunities and unequal access to education for other types of foreign students relatively.

\section{Education Management System on Education for Foreign Children in Japan}

\subsection{Earlier Construction of Education Management System on Education for Children}

In 1990s, facing the labor shortage, the Japanese government amended the "Import and Export Administration and Refugee Recognition Act" to loosen restrictions on entry requirements for foreigners. Since then, the number of foreign students in Japan has increased significantly. How to improve the admission management system for foreign students in primary and secondary schools has become an important issue in the Ministry of Education of Japan in the 1990s. Today, with the promulgation of policies such as "Memorandum Between Japan and South Korea", "The Configuration of Teachers for Foreign Students in Need of Learning Japanese", "Promotion of Education Internationalization by Returning Children and Foreign Students Jointly", "Handbook on Foreign Students' Admission", “Guidebook for Foreign Students' Schooling”, "Model on Educational Support System for Foreign Students and Returning Students", 
"Document on Enriching the Education of Foreign Students", "Document on Promoting the Admission of Returning Students and Foreign Students", Japan has formed a relatively complete system of receiving foreign students in primary and secondary schools, which should provide meaningful reference for China appropriately.

\subsection{Main Characteristics of Education Management System on Education for Children}

1) Adhere to ensuring that foreign children in compulsory education age enjoy national treatment in public primary and secondary schools.

First of all, as long as the foreigners register with their residences, their age appropriate children, regardless of their Japanese language ability, can be exempted from test to be admitted into public primary and secondary schools without any fees. Secondly, the local education committees fully acknowledge the situation of foreign children's school-entrance and dropout in the areas within jurisdiction through the implementation of the "pre-school physical examination for children" and the distribution of the "Schooling Guideline" to guarantee the learning rights of all foreign students. For the foreign students who are finally enter in local schools, the relevant departments of the Education Committee will illustrate related matters about the admission for the guardian after confirming the residence address and accepting the "application for admission or transfer", so that the guardian can fully understand the Japanese school education system as well as function and operation of PTA. For children who drop out of school, the Japanese government is also actively taking measures to promote their school attending. For example, the Chiba County Board of Education will ask for a person in charge to conduct a home visit to persuade the guardian to send the child to the school [12].

2) Establish a tripartite cooperation system among the "Ministry of Education, Science and Technology" the education committees and schools in various regions to promote the improvement of the management system for foreign students at school level.

Firstly, the Board of Education provides human resources support to the schools. The main forms include the dispatch of Japanese instructors, translators and foreign students teaching assistant volunteers to the school, while providing regular training for Japanese language instructors etc. Secondly, the Education Board provides financial support for opening Japanese language classrooms and for editing textbooks by various language versions. Finally, the Education Board organizes the heads of the districts to conduct enrollment briefings for secondary schools and high schools what is convenient for parents of graduates to acknowledge relevant information. Besides, under the goal of creating a multicultural symbiotic society, the Education Board regularly organizes communications between experienced schools and less experienced schools for encouraging latter one learning teaching management experience for foreign students 
3) Systematically improve the school education management system for foreign students.

First of all, special faculty will be arranged to communicate with the guardian for parents fully understanding on the school teaching management meanwhile building trust relationship with each other after foreign students' school entering. At the same time, cooperate with the Board of Education after understanding the specific needs of students and ask for assistance about Japanese teachers-sending or Japanese classes-opening. Secondly, develop a systematic teaching system for meeting the needs of foreign students involving the staff of the whole school as far as possible under the principle of strengthening international understanding education [13]. Such as the measures like helding foreign parents' consultation or strengthening system of Japanese language teaching and graduates' academic and career counseling etc. Finally, focus on regional cooperation. For example, building up the strong relationship between parents and PTA, enhancing students' awareness on the community, and recruiting Japanese language volunteer teachers.

In addition, the Ministry of Education, Science and Technology also proposed "further strengthen system of the graduates' graduation guarantees", "protect the mother language and the culture of the students" and "eliminate the dropping out of school" as the key development topics of the future education management system. All these measures and implementations are enacted under the international conventions' concept that all children must be guaranteed educational rights regardless of nationality or ethnicity, and equal opportunity for education and the receipt of free education for all children is the minimum request.

\section{Conclusions}

The education opening policies in China have been inevitably influenced by various factors including the international situation, the international relations, the international political and economic environment and the development conditions of the nation while being made then. These policies require reorganization, rearrangement, and perfection so as to meet the current and future requirements for further opening to the world of the Chinese education.

After joining the World Trade Organization, China's education market is gradually opening up. Judging from the current situation of the implementation of management policies on education for foreign students in primary and secondary schools in Shanghai, it's clarified that China's basic education market is also facing the impact of the international tide. Therefore, sorting and analyzing the relevant policies for the foreign students' education management in primary and secondary schools formulated in 1999 (national) and 2000 (Shanghai), then providing suggestions for improving the education management system for foreign students in primary and secondary schools, play a positive role in the internationalization of basic education in China. 
Based on comparison between China and Japan, the following four points are worth learning in improving the education management system for foreign students in primary and secondary schools.

Suggestions on Improving the Education Management System of Primary and Secondary Schools are:

1) Focusing on the development of Chinese teaching system: First of all, strengthening the training of TCSL teachers for foreign students at school age by means of the training platform for TCSL teachers; secondly, improving the design of Chinese language teaching for foreigner students. In particular, the teaching content should not only be limited to the test-oriented language teaching but also formulate corresponding Chinese language teaching plans in accordance with foreign students' different growth and learning background (such as nationality, Chinese language learning experience, Chinese language learning environment in home and others).

2) Enhancing the cooperation of all departments at the school level and improving the school teaching management system. First of all, the faculty and staff of the whole school must fully understand the importance and particularity of education on foreign students involved in all from the management of student status, teaching management to logistics management; secondly, improve various rules and regulations while clarifying the work arrangements for the education on foreign students in all administrative departments based on the viewpoint of education internationalization especially on the textbook compilation and teaching aids (such as setting up Chinese language learning system, faculty members experience exchange system, overcoming cultural and custom differences), all departments need to communicate and cooperate with each other.

3) Strengthening the formulation of specific policies at all levels of administrative departments of education, and tightening the cooperation among the administrative departments of education, schools and foreign students' parents. According to the current system, the responsibility of the administrative departments of education at all levels in cities and districts (counties) is relatively clear. However, it is still out of order in terms of teachers training, teaching planning, and curriculum designing which requires further guidance and support as well as more terms and conditions from the executive branch. At the same time, it is necessary to strengthen up the connections between schools and parents such as trying to build a platform for "promoting communication between parents and the education administrative departments", or a platform for "exchanges on experience in teaching and management among schools" or a platform for "promoting cooperation between home and school".

4) Considering the diversity of foreign students and protect their different cultural traits. These diversities are mainly reflected in language, culture, family environment, and the purpose of coming to China, the length of time in China and others. For these foreign students with various backgrounds, how to maintain their own mother language, native culture characteristics, religion and living 
habits (especially foreign students in primary school) is a point of attention for future institutional improvement.

\section{Fund Program}

The National Social Science Fund of China under Grant 15BGL107.

\section{Conflicts of Interest}

The authors declare no conflicts of interest.

\section{References}

[1] Li, A.M. (2010) 20000 Foreign Students Studying in Shanghai Primary and Secondary Schools. http://roll.sohu.com/20101114/n300287962.shtml

[2] Yan, W.L. (2005) Perspective on the Education for Foreign Students' in Primary and Middle school. Modern Primary and Secondary Education, 11, 5-7.

[3] Li, C. (2010) Shanghai's Urban Key Middle Schools Spread to the Suburbs, the International Class Become a Common Practice. http://news.sohu.com/20100513/n272086915.shtml

[4] Taiji, K.Y. (2009) The Number of Children Is the First in the World: Shanghai Japanese School. Record of Teaching Practices at Overseas Educational Facilities, 31, 269-271.

[5] Zhao, X. and Song, H.Y. (2010) Intercultural Education and Management in the Field of Basic Education: A Case Study of Three Shanghai Schools Accepting Foreign Students learning in Regular Classes. Basic Education, 9, 29-33.

[6] Chen, J. (2008) Study on the Management of Overseas Students Learning in Regular Class: Taking Shanghai New Basic School as a Case. PhD Dissertation, School of Public Management of Huadong Normal University, Shanghai.

[7] Gao, L. (2006) Over 50 Million Foreigners Working in Shanghai. http://www.china.com.cn/chinese/news/1267726.htm

[8] Bureau of Statistics (2011) Hong Kong, Macao and Taiwan Residents and Foreign Personnel Census Data. http://www.gov.cn/gzdt/2011-04/29/content 1854902.htm

[9] Zen, T.S. (2002) Study on the Influence and Countermeasures of Joining WTO on China's Education. Forum on Contemporary Education, 4, 5-12.

[10] Chen, R.P. and Su, H. (2010) Analysis on the Internationalization of Basic Education in China. Contemporary Educational Science, 14, 3-7.

[11] Yang, A.M. (2000) Join the WTO: Challenge and Countermeasures of Elementary Education. Qunyan, 7, 10-18.

[12] Ministry of Education, Culture, Sports, Science and Technology of Japan (2001) Guide to Foreign Students' Admission. http://www.mext.go.jp/a menu/shotou/clarinet/002/1304668.htm

[13] Satou, G.I. (2010) Cross-Cultural Education-Movement between Cultures Children's Education. Akashi Press, Tokyo. 